\title{
A Ética como Competência Profissional na Formação: o pedagogo em foco
}

\begin{abstract}
Sheyla Maria Fontenele Macedo'
Ana Paula Viana Caetano"

'Universidade doEstado do Rio Grandedo Norte(UERN), PaudosFerros/RN-Brasil "Instituto de Educação da Universidade de Lisboa (IEUL), Lisboa-Portugal

RESUMO - A Ética como Competência Profissional na Formação: o pedagogo em foco. Este artigo visa compreender a ética como competência profissional transversal e autônoma no campo da formação do pedagogo. Discute as temáticas da competência e competência profissional; da ética, ética profissional como competência no cerne da formação do pedagogo. É pesquisa de cunho qualitativo, assente na revisão de literatura de renomados pensadores na esfera das competências profissionais. Dialoga especialmente com Boterf (2003), Caetano (2010), Estrela e Silva (2010), Garcia (1999) e Perrenoud (2000). Inaugura a discussão da ética enquanto dimensão práxis transversal e competência máxima no corpo da formação profissional. Palavras-chave: Ética. Competência Profissional. Formação. Pedagogo.
\end{abstract}

\begin{abstract}
Ethics as a Professional Competence in Training: the pedagogue in focus. This article aims to understand ethics as an autonomous and transversal professional competence in the field of pedagogues' training. It discusses the aspects of competence and professional competence; of ethics, professional ethics as competence in the core of the pedagogues' training. Ii is a qualitative research, based on the literature review of renowned thinkers in the field of competences. It dialogues especially with Boterf (2003), Caetano (2010), Estrela and Silva (2010), Garcia (1999) and Perrenoud (2000). It inaugurates the discussion of ethics as a transversal dimension of praxis and maximum competence in the body of professional training. Keywords: Ethics. Professional Competence. Training. Pedagogue.
\end{abstract}

Educação \& Realidade, Porto Alegre, v. 42, n. 2, p. 627-648, abr./jun. 2017. 
A Ética como Competência Profissional na Formação

\section{Considerações Iniciais}

Neste artigo pretendeu-se empreender um jogo epistemológico interativo, a partir da combinação de três categorias teóricas que no campo da educação não se tem constatado grande dialeticidade: a) A competência, seu âmbito profissional; b) A ética enquanto competência profissional; c) A formação do pedagogo. Na intenção de revolver as temáticas, de cunho inovador, especialmente no campo da Pedagogia, idealizou-se uma rota, de certa forma rebuscada, visto que, as discussões no campo da ética profissional do pedagogo ainda são caminhos a serem percorridos, dadas as escassas produções no âmbito da conjuntura apresentada. Lacunas maiores se encontram no terreno da ética enquanto competência. Pretendeu-se revelar a ética como dimensão necessária no cerne do desenvolvimento da competência profissional, numa perspectiva humanística, buscando-se o distanciamento do prisma neotecnicista. As questões apresentadas foram, na verdade, toque de partida para a reflexão da ética enquanto dimensão práxis transversal, e enquanto competência macro, conceitos estes inaugurados neste artigo, na intenção de gerar novos jogos interativos.

Para realizar tal trajetória, enveredamos por algumas fontes teóricas, tais como, Machado (2002), que define os elementos fundamentais das competências; Boterf (2003) e Perrenoud (2000), que inovaram o campo das competências profissionais por apresentarem seus modelos sistêmicos; Estrela e Silva (2010) e Caetano (2010) pelas reflexões de que a ética profissional emerge da ética, em contextos específicos de exercício profissional; Garcia (1999) por nos remeter às concepções de formação, Sacristán (2000), Diáz Barriga (1990) a fim de discorrer as reflexões sobre o currículo do campo da formação, dentre outros não menos relevantes.

Como resultado principal, pronunciamos que, além da produção dos conhecimentos sobre competência ética profissional, esta dimensão deverá ser forjada no cômputo da formação inicial do pedagogo.

\section{Desatando nós Epistemológicos: competência e competência profissional}

Nesta primeira parte das discussões duas ideias fundamentais foram abordadas, a de competência e as questões que fundamentam $o$ corpo teórico acerca da competência profissional.

Para início de jogo, recordamos que no senso comum o vocábulo competência está associado à ideia de alguém que faz bem algo ou alguma coisa. O que permite identificar três características que envolvem o conceito. $\mathrm{O}$ primeiro de que ser competente é um estado inerente à pessoa, a pessoalidade (Machado, 2002), já que afirmações tais como "Meu computador é extremamente competente", ou "Tenho um livro muito competente" (Machado, 2002, p. 141) causariam estranhamento. Num segundo momento, se é competente na ação de fazer algo com o fim de ou para. E em último término, a competência se vincula ao sentido 
de bem, de algo que seja bem feito, bem executado e que bem resulte. Logo, alguém que é competente, naturalmente tem em conta que algo a ser feito necessita ser bem feito. O que de alguma forma se aproxima do conceito de ética enquanto reflexão e prática do bem pensar, agir, fazer, viver.

De acordo com Machado (2002) a concepção de competência se define a partir de outros elementos fundamentais além da pessoalidade: o âmbito, as habilidades, a mobilização de saberes, a interdisciplinaridade e a contextualização.

A ideia de âmbito denota que uma competência se produz dentro de um ambiente que lhe seja natural, ou seja, cada competência possui o seu habitat, carece de uma referência, de um determinado espaço para se potencializar. Desta forma, por exemplo, a competência oratória de um político ou de um advogado numa audiência desenvolve-se e concretiza-se em ambientes diferenciados.

No que se refere à ideia de habilidades, de acordo com Machado (2002) estas se configuram na proficiência, eficiência e capacidade inerentes a uma competência. Ou seja, no cerne de uma competência, assim como a do bem redigir, várias habilidades (capacidades) são necessárias desde as mais simples, as mais complexas, nomeadamente: a de manejar a caneta (ou digitar teclas de um computador), a do processo de codificação da língua, a seleção das melhores palavras, etc. Em resumo, uma competência necessita de um âmbito para se desenvolver, e cada âmbito por sua vez, incrementa uma ou mais habilidades no corpo de uma dada competência.

No que se relaciona a mobilização de saberes, estes seriam para Machado (2002) como esquemas de ação dos conhecimentos, ou na forma que estes se mobilizam na e para a consecução de uma competência. Retornando ao exemplo da competência para escrever, seria necessário o conhecimento da língua e das articulações entre o gráfico, o ortográfico e a sintaxe. O que nos remete aos conhecimentos não formais aprendidos com a experiência e os formais apreendidos particularmente na escola, na área de Língua Portuguesa.

A característica da interdisciplinaridade diz respeito à circunstância em que uma competência se encontra imbricada com as várias áreas do conhecimento, e como se processa seu relacionamento com as demais competências. Portanto, sua aprendizagem não poderá ser tão somente ensimesmada, mas compartilhada.

No que tange à contextualização, conceitua Machado (2002, p. 150) que é uma "[...] estratégia fundamental para a construção de significações”. Ou seja, uma competência se processa num determinado texto e contexto de vozes, de comunicações, de âmbitos, de tempo, de espaço, de cultura. A competência para escrever hoje, não se gesta no mesmo contexto do profissional da área do jornalismo do século XIX, pois até o conceito de liberdade de expressão é outro.

Do exposto, concluímos que não se pode encapsular ou minimizar a ideia de competência, visto que a temática envolve uma série de enredos teóricos.

Educação \& Realidade, Porto Alegre, v. 42, n. 2, p. 627-648, abr./jun. 2017. 
A Ética como Competência Profissional na Formação

Avançando com o propósito deste artigo, elucidaremos o jogo da competência no campo profissional, já que até aqui abordamos a temática de forma geral.

Inicialmente faz-se mister responder o que é ser profissional? De forma elementar, porém objetiva, Boterf $(2003$, p. 37) explicita que "O profissional é aquele que sabe administrar uma situação profissional complexa". A assertiva nos remete a duas reflexões: o conceito de situação e em qual trama esta se torna complexa. A noção de situação enunciada por Boterf (2003) refere-se a uma circunstância profissional específica, que embute um determinado grau de complexidade, que vem a requerer uma rápida atitude e prontidão para pensar e agir de forma antecipada e por vezes inédita frente ocorrências que poderiam ser corriqueiras, mas que por vezes se metamorfoseiam em estados adversos e incidentais. O que em suma quer dizer que o profissional deverá saber "[...] tomar iniciativas e decisões, negociar e arbitrar, fazer escolhas, assumir riscos, reagir a contingências, panes ou avarias, inovar no dia a dia e assumir responsabilidades" (Boterf, 2003, p. 38).

Na mesma linha reflexiva, e na intenção movimentar o jogo conceitual sobre competência profissional questiona-se ainda: O que significa ser um médico, um enfermeiro, um professor, um pedagogo competente? Quando se afirma que este ou aquele é um profissional competente, o que se visa é demarcar a linha divisória entre os profissionais que são competentes daqueles que não o são. Perrenoud et al. (2001, p. 27) define um conceito de competência profissional para o professor, o que em nosso entendimento se aplica as demais profissões: "[...] o conjunto de competências formado por conhecimentos savoir-faire e posturas, mas também ações e atitudes necessárias ao desenvolvimento da profissão [...]". Outros questionamentos se combinam à questão de partida: Um profissional é competente o tempo inteiro e em todos os campos de sua ação? Um profissional competente é aquele que denota em seu comportamento um somatório de competências adquiridas? Um modelo de formação centrado no desenvolvimento de competências não nos levaria à formação de profissionais em série? É provável e possível forjar um programa de formação no domínio da educação, cujo currículo esteja voltado para a criação de um profissional competente? O que dizer de todo este jogo, jogado no campo da Pedagogia?

Inicialmente, a competência profissional é entendida no singular como qualidade global, que atesta o profissionalismo e a profissionalidade (Frade, 2014). Assumimos aqui o conceito de competência profissional a partir de um âmbito plural, isto é, o de competências. Ou seja, ao afirmar que um profissional é competente, subentendemos que ele reúne um conjunto de competências que assim o qualificam. Adiantamos que o que propomos neste ensaio, é a inclusão da dimensão ética como macro competência nesta robusta estrutura.

Considerando a pluralidade embutida no conceito de competência profissional, concebemos duas abordagens teóricas no que se refere à discussão sobre as bases epistemológicas em que se assentou este conceito no âmbito das Ciências da Educação, no sentido de melhor 
localizar as posições teóricas que admitimos acerca das competências profissionais.

A ideia de competências profissionais surge na conjuntura das investigações sobre o desenvolvimento humano a partir de uma perspectiva behaviorista. Seriam estas competências operacionalizadas por micro partes, ou micro competências, por exemplo, a competência para a leitura incorpora uma série de micro competências para que se possa chegar ao domínio do ato de ler com destreza. Foi com base nesta concepção que o avanço dos referidos estudos se justificaram entre as décadas 60 e início de 80 do século XX, nos Estados Unidos. Desta maneira, foram organizados programas de formação de professores, que dentre as várias características destacamos "[...] a especificação precisa das competências ou comportamentos a serem aprendidos" (Swanchek; Campbell, 1981, apud Esteves, 2009, p. 39). Evidenciamos nesta linha dois programas específicos, o denominado Competency Based Teacher Education - CBTE, baseado em competências observáveis e o Performance Based Teacher Education - PBTE, que consistia em desvendar qual seria a melhor performance para se forjar um professor eficiente. A finalidade comum de produzir desempenhos docentes de excelência foi a razão assinalada para que os referidos programas passassem a ser conhecidos como um só, Performance/Competency Based Teacher Education (P/CBTE) (Esteves, 2009).

Esteves (2009) revela críticas quanto a formação baseada nos modelos de micro competências por duas fortes razões: a) O perfil de profissional bem-sucedido não se limitaria a uma lista de competências isoladas; b) A ausência de evidências científicas que comprovassem a eficácia dos programas (Esteves, 2009). Em nosso entendimento, uma tábua infindável de micro competências não só se constituiria em aquisição e prática improvável como mecanizaria o humano em seu âmbito profissional. Desta forma, nos distanciamos da ótica comportamentalista, da aquisição de competências profissionais no domínio da educação enquanto rol esmiuçado de competências a serem desenvolvidas. Não seria esta uma tentativa de estandardizar o humano contido no profissional?

A segunda abordagem teórica sobre o campo da competência profissional é, de acordo com Pires (2005), a de caráter sistêmico, de sentido integrador. Esta abordagem embute a articulação entre as diversas esferas de competências necessárias ao ser humano, seus múltiplos saberes, suas atitudes, hábitos, etc. Destacamos duas principais características que conseguimos depreender deste enfoque. Primeiro porque desafia a integração entre os campos do desenvolvimento profissional e o pessoal:

O desenvolvimento profissional, na sua ligação com o desenvolvimento pessoal, implica que o indivíduo esteja inserido numa situação profissional em que utilize as suas capacidades de raciocínio, de criatividade, de tratamento de informação, de comunicação com os chefes, colegas e colaboradores, de resolução de problemas, de concertação interdisciplinar, etc. (Le Bouedec, 1988, p. 263). 
A Ética como Competência Profissional na Formação

Em segundo lugar, e a partir da compreensão da composição natural existente entre os dois campos de desenvolvimento assinalados, a abordagem de competência sistêmica expande a ideia já discutida de situação complexa em Boterf (2003), na promoção da troca interativa entre os domínios do espaço profissional e as demais conjunturas que modelam a escultura humana.

Para uma melhor compreensão desta linha sistêmica e complexa, Allal (2004, p. 83) esclarece que a competência “[...] é uma rede integrada e funcional constituída por componentes cognitivos, afetivos, sociais, sensório-motores, capaz de ser mobilizada em ações finalizadas diante de uma família de situações".

Alinhamos com esta premissa por sua característica integradora, globalizadora, de totalidade, já que o paradigma behaviorista nos levaria à permuta da hierarquia dos conhecimentos, dos saberes, das práticas, da autonomia do profissional no âmbito da tomada de decisões, para uma verticalização comportamental, da competência limitada a um modus operandi. Outro ponto significativo que nos remete à competência profissional sob a ótica sistêmica nos é revelado por Esteves (2009, p. 41):

\begin{abstract}
[...] estudos realizados na Europa continental em diversas áreas da formação profissional que não exclusivamente a de professores foram pondo em evidência que os profissionais excelentes apresentavam um conjunto de competências genéricas ou globais bem mais importantes para explicar o seu sucesso do que as competências analíticas muito numerosas a que a análise das funções laborais tinha conduzido (grifos nossos)
\end{abstract}

Nesta linha reflexiva vários modelos poderiam ser elucidados, destacamos os de Perrenoud (2000) e o de Boterf (2003) em razão de sua característica de organização holística.

Perrenoud (2000) ao definir as dez categorias que integram o corpo de competências necessárias ao professor, descontrói o modelo de micro competências, permitindo maior flexibilidade e exiguidade à condição de vir a ser competente, já que uma lista interminável de competências poderia se tornar impraticável e, portanto, gerar desmotivação no exercício profissional.

Consideramos invulgar o fato de Perrenoud (2000) elevar e incluir a dimensão ética nesta lista das dez mais, ainda que numa perspectiva limitada a instância das problemáticas sociais, das rupturas éticas existentes na sociedade, tais como a luta frente aos preconceitos e discriminações, às regras na escola, as relações sociais, à formação de valores e sentimentos, em especial, o de justiça. Entretanto, sua inclusão abre espaço para um novo debate, o da ética enquanto competência autônoma.

O modelo apresentado por Boterf (2003) apesar de se tratar de uma discussão acerca da competência profissional de forma genérica, e não se direcionar especialmente à educação, em nosso entendimento, é afim ao campo de interesse no que tange à formação do pedago- 
go. Para melhor compreender esta assertiva, antes avançar quanto as discussões do modelo proposto por Boterf (2003), julgamos necessário realizar uma breve digressão sobre os espaços que no campo do legal são reservados nos dias de hoje à ação profissional do pedagogo, sem a intenção de nos aprofundarmos quanto à especificidade de seu trabalho, em cada um destes espaços (escolares e não escolares). A inserção deste parêntese se justifica a partir do intuito de favorecer uma melhor compreensão do jogo epistemológico entre as categorias teóricas ética profissional e formação do pedagogo, que serão elucidadas à frente.

A Lei $\mathrm{n}^{\circ}$ 9.394, de 20 de dezembro de 1996, ou Lei de Diretrizes e Bases da Educação no Brasil, mais conhecida como LDB, regula que a formação do profissional que poderá atuar no ensino de crianças até aproximadamente 11 anos, ou seja, da Educação Infantil às primeiras séries do Ensino Fundamental, e cuja far-se-á em curso de licenciatura plena, nível superior ou em nível médio, na modalidade normal (Brasil, 1996), ou seja, o pedagogo. A respectiva legislação é ainda complementada pelas Diretrizes Curriculares Nacionais para o Curso de Pedagogia no Brasil (Brasil, 2006), e que em seu artigo $4^{\circ}$, faz referência a que esta formação se estenda a outros campos profissionais, tais como "[...] na área de serviços e apoio escolar e em outras áreas nas quais sejam previstos conhecimentos pedagógicos" (Brasil, 2006, p. 2), e atividades docentes em espaços "[...] não-escolares, na promoção da aprendizagem de sujeitos em diferentes fases do desenvolvimento humano, em diversos níveis e modalidades do processo educativo" (Brasil, 2006, p. 2).

Desta forma, poderá o pedagogo exercer suas atividades profissionais em áreas diversificadas, que se assentam não somente sobre os pilares da docência, mas da gestão dos processos educativos, abrindo novos campos para a ação pedagógica, os espaços não escolares (Macedo, 2014).

Retomando as ideias de Boterf (2003), entendemos ser o seu modelo de competências correlato com a natureza do trabalho do pedagogo por cimentar o incremento das competências profissionais a partir de uma súmula de saberes interativos entre si, o que vai ao encontro da diversidade dos espaços profissionais abrangidos por este profissional. Boterf (2003) elenca mais especificamente seis saberes: 1. Saber agir com pertinência. 2. Mobilizar saberes e conhecimentos em um contexto profissional. 3. Integrar ou combinar saberes múltiplos e heterogêneos; 4. Saber transpor; 5. Aprender a aprender a aprender; 6. Envolver-se (Boterf, 2003, p. 38).

O saber pertinente está associado ao saber agir (Boterf, 2003, p. 38) em situações de imprevisibilidade que exijam decisões complexas e adequadas às situações, postura diferente do saber fazer para:

O saber agir não se reduz ao savoir-faire ou ao saber operar. O profissional deve não somente saber executar o que é prescrito, mas deve ir além do prescrito. Se a competência se revela mais no saber agir do que no 'saber fazer', é porque ela existe verdadeiramente quando sabe encarar 
A Ética como Competência Profissional na Formação

o acontecimento, o imprevisto. Em última análise, não é necessário ser competente para executar o que é prescrito, para aplicar o que é conhecido. $\mathrm{O}$ 'saber fazer' referente à execução não é senão grau mais elementar da competência.

No que refere a saber mobilizar conhecimentos em um contexto profissional, Boterf (2003) compreende que nem sempre possuir conhecimentos ou capacidades, habilita o profissional a atinar como melhor aplicá-los ou o tempo oportuno para fazê-lo. Em outras palavras, não basta ter um curso teórico de pilotagem para saber, por exemplo, aterrissar num aeroporto.

Boterf (2003, p. 56) revela que existe um repertório de saberes a serem utilizados nas diversas atividades que integram uma profissão. Estes são múltiplos e heterogêneos, e exigem o desenvolvimento de uma capacidade interativa, integradora entre os mesmos, ou o conhecimento de como forjar uma "[...] arquitetura cognitiva particular da competência, uma combinatória pertinente de múltiplos ingredientes que terão sido selecionados conscientemente". Assim, quando alguém aprende a dirigir, deverá combinar inúmeros saberes em tempo real, tais como a passagem da marcha, o controle dos pedais, a visão periférica, o conhecimento das leis de trânsito, etc.

Um saber complementar aos apresentados é o da transposição (Boterf, 2003, p. 70), ou em outras palavras, a capacidade de deslocar conhecimentos de atividades profissionais para situações e contextos distintos. As competências deverão ser, portanto, “[...] cada vez mais transponíveis. Elas não poderiam permanecer inertes diante da variabilidade dos contextos".

$\mathrm{O}$ aprender a aprender a aprender se desenvolve no saber extrair conhecimentos da experiência, logo, transformar este aprendizado em ação, ou seja, em experiência que se extrai da experiência. Neste ponto, o profissional saberá aprender de acordo com Argyris (apud Boterf, 2003) por circuito simples, quer dizer, usar o aprendido de modo diferente na ação, sem cambiar teorias, valores, etc. Ou por circuito duplo, quando para agir, mudará, inclusive, as teorias construídas, os esquemas padronizados que fundamentam à ação.

O envolvimento refere-se ao nível de comprometimento com a profissão, ou seja, a implicação individual para com o quadro coletivo profissional. Coincide ainda com a capacidade afetiva de zelar pela atividade a qual é responsável. Entretanto, para Boterf (2003, p. 81), envolver-se não é assim um saber tão evidente, visto que "[...] levanta questões difíceis, particularmente no estabelecimento dos contratos de trabalho. Como determinar de antemão o nível requerido de implicação quando a capacidade de antecipação dos acontecimentos e da evolução do ambiente é limitada?".

Naturalmente que aqui realizamos uma concisa explanação das ideias de Boterf (2003), modelo sui generis, que consideramos adequado ao âmbito da formação do pedagogo, em razão da abrangência dos espaços de labor que envolve seu ofício. Um pedagogo que atue, por exem-

634 Educação \& Realidade, Porto Alegre, v. 42, n. 2, p. 627-648, abr./jun. 2017. 
plo, na Educação Infantil naturalmente necessitará de competências diferenciadas daquele que trabalha na modalidade de Jovens e Adultos, ou ainda nos espaços não escolares. Não há, portanto, um perfil padronizado ou tipificado para a ação pedagógica. Cada nível de ensino é um, cada currículo é um, cada prática é uma, cada aluno é um, cada classe é uma, e cada espaço, quer seja escolar ou não escolar tem a sua cultura. nado.

Desta forma, sintetizamos a seguir uma parte do jogo descorti-

Um profissional competente se forja a partir da integração entre o desenvolvimento pessoal e o profissional, por meio especialmente, dos processos formativos. Acolhemos a abordagem de competências assentada em modelos de ordem sistêmica, por admitirmos sua complexidade, pela concordância com as críticas tecidas aos programas baseados em micro competências e por consideramos seu teor de caráter humanista. Entendemos ainda que é preciso considerar que o desenvolvimento de competências tome como ponto de partida a formação inicial, distanciando-se do tecnicismo, contemplando por outro lado, a vertente reflexiva, de forma a possibilitar que o futuro profissional desenvolva a autonomia, a fim de ser capaz de negociar com seus pares, as competências necessárias para esta ou aquela situação profissional. É precisamente neste ponto que um recorte da ética se faz imprescindível como mote para se laçar este ideal.

\section{A Competência Ética Profissional: a formação do pedagogo em foco}

Neste bloco buscaremos realizar digressões sobre três pontos que se fazem de base para o jogo das categorias teóricas discutidas neste trabalho. Primeiro traçaremos algumas concepções sobre ética e as tessituras frente ao seu contexto profissional, em segundo término, os argumentos construídos acerca da ética nos domínios da competência e finalmente, reflexões sobre o âmbito da formação do pedagogo, que inclui uma incursão no campo curricular.

Concebemos como um norte na discussão complexa que envolve as temáticas da ética e da ética profissional as palavras de Estrela e Silva (2010, p. 43): "Se considerarmos a ética como a reflexão sobre a conduta humana que leva à fundamentação de princípios orientadores, a ética profissional poderá considerar-se a transposição desses princípios para as situações profissionais". O que nos remete a ideia de que a ética pode ser compreendida como atitude reflexiva da própria conduta social, e por sua vez, questionadora da moral, entendendo esta como "[...] um conjunto de normas e regras destinado a regular as relações dos indivíduos numa comunidade social dada" (Vázquez, 1987, p. 25). Nesta linha, a ética profissional emergiria da reflexão ética, em contextos específicos de exercício profissional.

A ética é ainda, uma dimensão medular da configuração psicobiológica (anímica e física) e espiritual (Pecotche, 2008) do ser humano, isto em função de vários aspectos, dentre eles, destacamos:

Educação \& Realidade, Porto Alegre, v. 42, n. 2, p. 627-648, abr./jun. 2017. 
A Ética como Competência Profissional na Formação

1. A ética está estreitamente vinculada à razão, pois toma elementos desta para que o ser humano possa forjar juízos, tomar decisões, resolver dilemas éticos, etc. E se a ética necessita da razão para criar reflexões, a razão humana se incrementa também a partir desta. O que nos leva a afirmar que a ética está para a razão e a razão para a ética;

2. A ética é fundamental nos processos de dialogicidade. De acordo com Cortina (2000, p. 67), os seres humanos se expressam pelo diálogo, meio fundamental para se conseguir chegar à felicidade. As éticas do diálogo veem o homem como "[...] ser capaz de comunicação e argumentação, como interlocutor”;

3. A ética é promotora na formação de valores positivos, forjando a edificação da dignidade humana;

4. É indispensável aos diferentes âmbitos da vida, torna o ser humano reflexivo e crítico da moral, e não subserviente aos códigos (Cortina, 2000).

Do exposto, entende-se que é a ética estruturante do caráter humano, e que, portanto, também o é no que se refere ao domínio profissional.

Situado este ponto de partida, nos pronunciamos sobre o jogo da ética profissional na esfera da competência.

Afinal, a ética profissional deve ser referida como uma competência autossuficiente, ou como dimensão atravessadora das demais competências ou ainda como micro competência? Na intenção de elucidar a querela, inauguramos neste trabalho dois conceitos no que tange a temática. Inicialmente recordamos que já descartamos a ideia da ética profissional sob a abordagem de micro competência. A ética por sua complexidade e essência estrutural do arcabouço humano não poderia ser encapsulada neste contexto. Compreendemos que a ética profissional no campo da discussão sobre competências se configura como: a) Dimensão práxis transversal; b) Competência macro, autônoma, independente e que se forja no âmbito da formação, não excluindo naturalmente, as relações estabelecidas com o terreno do desenvolvimento pessoal. Explicitemos.

A defesa da ética enquanto dimensão práxis transversal, ou seja, de que interpenetra as demais competências, assenta-se em razões já apresentadas, a característica estruturante da ética e o fato das competências possuírem embutidas o sentido do bem fazer. Na intenção de reforçar esta assertiva, tomemos as palavras de Rios (2001, p. 48):

\begin{abstract}
A ideia de bem parece-me significativa na definição de competência, porque ela aponta para um valor que não tem apenas um caráter moral. Ele não se desvincula dos aspectos técnicos nem dos aspectos políticos da atuação do educador. É nessa medida que se pode compreender, como veremos, a ética como mediação (grifos nossos).
\end{abstract}


Sá-Chaves (2005) e Tomaz (2007) assinalam ainda que a noção de competência possui quatro componentes básicos, de natureza “[...] técnica, relacional, crítica e ética” (Sá-Chaves, 2005, p. 9, grifo nosso).

Logo, pode-se concluir que a ética possui caráter transversal/mediador e se constitui em natureza, substância da noção de competência, e seu sentido de bem fazer nos remete a ideia de que toda competência estaria munida de um componente ethos.

Nesta linha reflexiva, tomamos como exemplo a competência global de Organizar e dirigir situações de aprendizagem e suas referidas competências específicas, extraída do modelo de dez competências de Perrenoud (2000) (Quadro 1).

\section{Quadro 1 - Competências específicas da competência global de organizar e dirigir situações específicas de aprendizagem}

\begin{tabular}{|l|l|}
\hline Competência global 1 & \multicolumn{1}{|c|}{ Competências mais especificas decorrentes } \\
\hline \multirow{2}{*}{$\begin{array}{l}\text { Organizar e dirigir } \\
\text { situações de } \\
\text { aprendizagem }\end{array}$} & $\begin{array}{l}\text { 1. Conhecer, para determinada disciplina, os conteúdos } \\
\text { a serem ensinados e sua tradução em objetivos de } \\
\text { 2. Trabalhar a partir das representações dos alunos. } \\
\text { aprendizagem. } \\
\text { 4. Construir e planear dispositivos e sequências didáticas. } \\
\text { 5. Envolveros alunos em atividades de pesquisa, em projetos } \\
\text { de conhecimento. }\end{array}$ \\
\hline
\end{tabular}

Fonte: Perrenoud (2000)

Conciliamos assim, que para que cada uma das competências específicas apresentadas, derivadas da competência máster (Organizar e dirigir situações de aprendizagem), pode-se extrair um recorte da ética como dimensão necessária. Por este ângulo, destacam-se a partir do exemplo pelo menos dois sentidos éticos, o primeiro, já debatido, o do bem fazer, entendido aqui como o bem do aluno, focado nas condições de seu processo educativo, em sua aprendizagem e o segundo, na rota da ética da alteridade (Ricoeur, 2011), assentada em três componentes, "[...] o desígnio de uma vida boa, com e para os outros, em instituições justas” (p. 5). Isto porque compreendemos ser imprescindível forjar um ponto de articulação com o outro para que se culmine o ciclo da relação ensinar-aprender.

Abordaremos nossa concepção sobre a ética enquanto competência autônoma, macro competência da ainda mais geral competência profissional. Consideremos como ponto de referência a afirmativa advinda do senso comum: este profissional é ético. A assertiva nos remete à reflexão de que a ética é nesta perspectiva uma competência embutida no estado de ser. O ser profissional. Mas o que de fato significa ser um profissional eticamente competente? Compreendemos que as bases da 
A Ética como Competência Profissional na Formação

ética se sustentam na triangulação: a) Conceitual e axiológica, do que se pensa, compreende e valora, a partir do campo conceitual; b) Deontológica, a ética do dever e dos princípios definidos a priori nomeadamente no campo profissional; c) Contextualista e consequencialista, do que se entende ser ético num contexto particular, atendendo às circunstâncias e às consequências previsíveis da ação. Consideramos, assim, a relevância de um bem pensar e de um bem sentir, para um bem agir em contexto:

Trata-se de uma aliança entre o conhecimento e a ação, pela qual o saber é sempre em permanente problematização, sempre inconcluso, ele próprio em transformação e gerando transformação da ação. O pensamento complexo reconnait les incertitudes de la connaissance, la difficulté de conscience, l'incertitude irrémédiable du devenir, et par la introduit aux incertitudes éthiques (Morin, 2004, p. 68).

Trata-se de um conhecimento dinâmico que se refaz à medida que se testa na ação e se recria com base nela. Trata-se de uma ação inteligente e criativa, intencionada e clarificada na compreensão dos contextos, na atenção vigilante às interações e no desvendar dos significados [...]. Uma responsabilidade - a nascer de uma compreensão, mas também de um sentir; uma compreensão - a nascer de uma responsabilidade e a desenvolver uma sensibilidade ao outro (Caetano, 2010, p. 10).

Desta conjuntura, resplandece a macro competência ética profissional, que por sua vez também costura as demais competências, discussão já abordada e argumentada.

Visando culminar os objetivos propostos para este artigo, projetamos nossas ideias sobre a ética como competência macro a ser desenvolvida no âmbito da formação do profissional de Pedagogia, quer este atue no espaço escolar ou não escolar.

A ética é essencial ao cerne de qualquer ofício. No caso do pedagogo, esta se incrusta no processo educativo (ensino-aprendizagem), que ao se desprender, por exemplo, no corpo dos componentes do ensino (objetivos da educação, currículo, metodologia, recursos e avaliação), é promotora, reiteramos, de um estado de bem fazer, um bem pensar, um bem sentir em direção da obtenção do que significa o melhor na relação com o aprendiz. Logo, a competência ética profissional sob esta ótica cria o sentido de responsabilidade na seleção de um melhor currículo, de um melhor planejamento, do compromisso com uma "[...] avaliação do bom senso" (Macedo, 2013), e no caso da docência, de melhores aulas. Entretanto, o resultado da ética profissional como competência macro é processo que se arquiteta, principalmente, a partir de uma sólida formação, cujo conceito nos apoiamos nas ideias de Garcia (1999, p. 21):

[...] a formação, como realidade conceptual, não se identifica nem se dilui dentro de outros conceitos que também se usam, tais como educação, ensino, treino etc. Em segundo lugar, o conceito formação inclui uma dimensão pessoal de desenvolvimento humano global que é preci- 
so ter em conta face a outras concepções eminentemente técnicas. Em terceiro lugar, o conceito formação tem a ver com a capacidade de formação, assim como a vontade de formação. Quer dizer, é o indivíduo, a pessoa, o responsável último pela ativação e desenvolvimento de processos formativos, isto não quer dizer, já o afirmamos, que a formação seja necessariamente autônoma.

Naturalmente que nenhum modelo de formação possui autonomia absoluta, visto que vários fatores incidem sobre a mesma, dentre eles, os fundamentos da legalidade. Neste sentido, pontuamos que a história dos cursos de Pedagogia registra a alternância entre o bacharelado e a licenciatura desde o marco de sua primeira regulamentação em 1939, através do Decreto lei no 1.190 de 4 de abril, que inseriu o curso como uma das seções da Faculdade Nacional de Filosofia da Universidade do Brasil (Brasil, 1939). Importante mencionar que na respectiva lei não configurava a ética no corpo do currículo disciplinar de três séries. Desta forma, questionamos nos dias de hoje, qual o papel reservado à ética enquanto competência profissional no cerne das atuais Diretrizes Curriculares do curso de Pedagogia (DCCP).

$\mathrm{Na}$ investigação das DCCP, constatamos que a expressão ética aparece exatamente cinco vezes neste documento. No artigo $3^{\circ}$ é situada como um princípio a ser adotado no exercício da profissão e sugere que o pedagogo trabalhe com "[...] um repertório de informações e habilidades composto por pluralidade de conhecimentos teóricos e práticos, cuja consolidação será proporcionada no exercício da profissão" (Brasil, 2006, p. 1). Ou seja, a ética se firma no exercício profissional. $\mathrm{O}$ artigo $5^{\circ}$ se refere ao aluno egresso do curso de Pedagogia, caracterizando sua aptidão ao "[...] atuar com ética e compromisso com vistas à construção de uma sociedade justa, equânime, igualitária" (Brasil, 2006, p. 2). Identificamos a intenção da ética como competência a ser adquirida, ainda que a expressão não tenha sido utilizada. $\mathrm{O}$ artigo $6^{\circ}$ refere-se à estrutura do curso de Pedagogia, que para além de respeitar à diversidade nacional e a autonomia pedagógica das instituições (Brasil, 2006), teria de aplicar as dimensões física, cognitiva, afetiva, estética, cultural, lúdica, artística, ética e biossocial (alínea e), em práticas educativas, ou seja, a ética adjetivada como de caráter aplicativo. Na alínea $k$ do mesmo artigo, sugere-se dar "atenção às questões atinentes à ética, à estética e à ludicidade, no contexto do exercício profissional, em âmbitos escolares e não-escolares, articulando o saber acadêmico, a pesquisa, a extensão e a prática educativa" (Brasil, 2006, p. 4, grifos nossos). A expressão atenção significa neste texto exatamente o reconhecimento da negação, ou seja, da lacuna da ética nos currículos formais de Pedagogia. O artigo $8^{\circ}$ aponta a ética enquanto atitude a ser desenvolvida no estágio curricular, com vista a "[...] assegurar aos graduandos experiência de exercício profissional, em ambientes escolares e não-escolares”. (Brasil, 2006, p. 5). Este ponto também poderia ser um sinal da intenção de que a formação profissional viesse a tomar a ética como um comportamento observável, e por sua vez, uma competência. 
Do exposto registramos, portanto, a ausência de um arremate nas DCCP no que tange ao formato sobre como a ética deve ser tratada nos cursos de Pedagogia, abrindo brechas no campo dos projetos pedagógicos curriculares (Macedo, 2014), facultando ainda outras lacunas: queremos ou não profissionais da educação eticamente competentes? $\mathrm{E}$ de que forma a competência ética profissional deverá ser abordada nos cursos de Pedagogia?

As referidas questões nos remetem ao aprofundamento do jogo interativo entre a formação e a temática curricular. Inicialmente, e para fins de esclarecimentos, não é objetivo deste artigo traçar a defesa ou contra-argumentação de um currículo por competências, que se traduz num campo de debates (a favor e contra) entre diversos autores. Nossa pretensão neste artigo é a de reunir argumentos para justificar a posição de legitimação a favor de uma formação consistente que contemple o desenvolvimento da competência ética profissional nos cursos de Pedagogia, e a partir daí, buscar uma configuração curricular includente desta perspectiva. Vejamos.

Consideramos como ponto de partida o conceito de cultura escolar apresentado por Viñao Frago:

La cultura escolar, así entendida, estaría constituida por un conjunto de teorías, ideas, principios, normas, pautas, rituales, inercias, hábitos y prácticas (formas de hacer y pensar, mentalidades y comportamientos) sedimentadas a lo largo del tiempo en forma de tradiciones, regularidades y reglas de juego no puestas en entredicho, y compartidas por sus actores, en el seno de las instituciones educativas (Frago, 2002, p. 59).

A definição nos remete à reflexão de que cada espaço educativo possui uma cultura escolar própria. Sacristán (2000) é eloquente nesta rota ao afirmar categoricamente que esta cultura escolar também interpenetra os currículos. E realiza ainda uma chamada de atenção ao referir-se aos valores no campo da moral que se incorporam nas diferentes culturas, que:

Todos esses valores fazem parte dos objetivos pretendidos e das atividades pedagógicas são parte de um currículo explícito da educação social e moral, e não cabe dizer que seja propriamente componentes de sua dimensão oculta. Embora a grande maioria dessas influências seja imposta como norma de fato, aceita sem discussão, como parte do que consideramos normal, e por isso são os elementos de uma socialização oculta (Sacristán, 2000, p. 132).

Do exposto, existem duas abordagens que nos interessam, a primeira de que a competência ética profissional intercede diretamente no processo de socialização do pedagogo no e para o mundo do trabalho; visto que socializar é, dentre outras noções, criar, produzir e compartilhar valores éticos. A socialização como parte do currículo formal nos cursos de Pedagogia deverá ainda:

640 Educação \& Realidade, Porto Alegre, v. 42, n. 2, p. 627-648, abr./jun. 2017. 
[...] provocar o desenvolvimento de conhecimentos, ideias, atitudes e pautas de comportamento que permitam sua incorporação eficaz no mundo civil, no âmbito da liberdade do consumo, da liberdade de escolha e participação política, da liberdade e responsabilidade na esfera da vida familiar (Gómez, 2000, p. 15)

O que nos remete à reflexão de que a função política, marcada pela atitude intervencionista no espaço público, também se incorpora à formação ética. Logo, é a socialização condição sine qua non nesta esfera profissional, isto porque o pedagogo tece relações humanas o tempo inteiro, revelando que o ser humano se constitui no eixo fulcral que alicerça seu compromisso perante a profissão.

Admitimos na segunda abordagem que os cursos de Pedagogia sustentam uma cultura ética profissional própria, em razão de que "[...] sem conteúdo não há ensino, qualquer projeto educativo acaba se concretizando na aspiração de conseguir alguns efeitos nos sujeitos que se educam" (Sacristán, 2000, p. 120). Contudo, como esta cultura se materializa? De forma explícita ou oculta, ou ambas? E até que ponto é intencional? De início, já identificamos no que tange ao corpo do legal, que foi reservado à ética um lugar pontual: o das adjacências da formação.

A respeito da questão sobre qual a cultura ética profissional que se desenvolve no campo da formação dos cursos de Pedagogia, entendemos que seria iminente uma imersão frente ao currículo em ação (referimo-nos aquele que se processa no lócus da prática pedagógica) para se identificar a partir dos resultados, as eficiências ou déficits, assim como as discrepâncias entre a teoria e prática. Cada cultura escolar produz um ethos profissional, que cria campos de variação na aplicação dos valores éticos, ou seja, a competência ética não pode ser encapsulada ou vinculada a um receituário do tipo vide bula. Por esta razão, alinhamos com Macedo (2006, p. 285) frente à premissa de que:

[...] a produção dos currículos formais e a vivência do currículo são processos cotidianos de produção cultural, que envolvem relações de poder tanto em nível macro quanto micro. Em ambos são negociadas diferenças. De ambos participam sujeitos culturais com seus múltiplos pertencimentos.

Reconhecemos que o sentido de pertencimento à uma determinada cultura exerce fortes pressões sob a edificação de comportamentos e da adoção de valores morais e éticos. Contudo, a competência ética a qual nos referimos mantém seu foco no sentido de bem, e hierarquiza o respeito à vida, em todas as suas formas de manifestação, acima de tudo. Este é um ponto fundamental a ser tomado em conta. Razão pela qual a ética que assumimos é de cunho humanista, mediada pelo crivo da reflexão. A privação de uma postura reflexiva induz o ser humano à obediência cega, à margem da formação de uma competência conscientemente construída, posição teórica que também admitimos neste trabalho. 
A Ética como Competência Profissional na Formação

O ponto que vem arrematar as últimas questões postas se encontra no fato de que uma formação da natureza especificada exige que os cursos de Pedagogia em primeiro lugar, despertem para a compreensão da ética como competência profissional necessária. A carência do entendimento da ética como parte estrutural da função social do pedagogo é uma das prováveis causas do vazio que se projeta frente à perspectiva de uma organização curricular que melhor se adeque às reflexões expostas. Este vazio gera um jogo de pula-pula metodológico, em que ora a ética se apresenta de forma explícita, quer seja na condição interdisciplinar, transversal ou no cerne das disciplinas da área de Fundamentos da Educação; ora ocultamente, implicitamente, assente no discurso de que a ética profissional se processa por meio do exemplo, ou seja, por osmose, como se os valores do professor se transmutassem para o graduando. Ora quiçá, facultada ao laissez-faire. Do exposto, não deixamos a questão posta completamente em aberto neste trabalho, mas a iluminamos mediante algumas rotas. Não descartamos, por exemplo, a alternativa da transversalidade como proposta de currículo aplicado. Entretanto, tomamos como advertência as premissas teóricas de alguns dos precursores das correntes críticas do currículo, tais como Apple (1989; 2006), Bernstein (1984; 1988), Giroux (1986; 1987), Young (1986; 1889), dentre outros, que "currículo é poder". Assim sendo, consideramos a transversalidade como forma de organização curricular, por vezes, rota de segunda linha, isto porque se apresenta como uma possibilidade, uma porta para que uma determinada temática seja abordada, porém sem garantia alguma de que seja realmente ressaltada, especialmente em seu caráter prático no corpo dos projetos pedagógicos de curso.

Barriga Diáz et al. (1990) sugere uma metodologia básica para a construção de um desenho curricular da educação superior, que nos interessou particularmente como um dos caminhos a ser percorrido, em razão da característica integradora da proposta, organizada em quatro etapas (Figura 1), a saber: 
Figura 1 - Etapas da Metodologia do Desenho Curricular

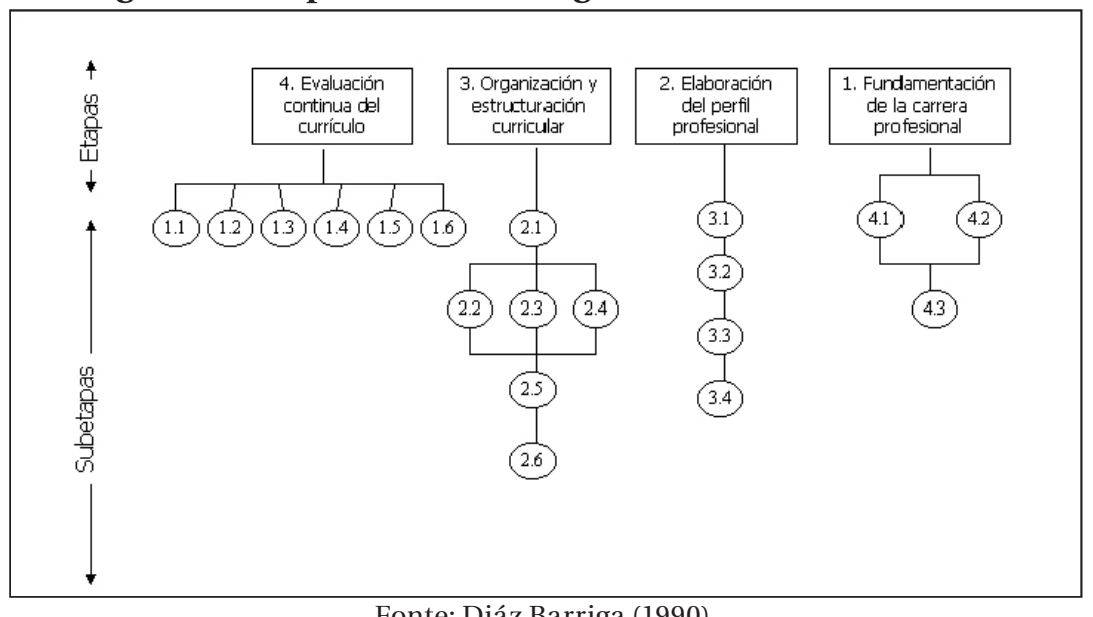

Na primeira etapa, os fundamentos da carreira profissional busca pontuar as necessidades a serem traçadas a curto e longo prazo na esfera dos parâmetros que sustentam uma profissão, levando-se em conta as variáveis dos contextos real e social que a dimensionam; e o ideal de sociedade. Concebemos necessário incluir como item primordial neste campo, os fundamentos éticos da profissão, cujas bases já discutimos neste artigo (conceitual/axiológica, deontológica e contextualista/consequencialista).

Na segunda etapa propõe Barriga Diáz et al. (1990) que se forje o desenho do arquétipo profissional de acordo com a fundamentação traçada e ainda: a) A investigação das áreas destinadas ao trabalho e dos conhecimentos, técnicas e procedimentos aplicáveis à solução de problemas profissionais; b) A análise das tarefas potenciais da profissão; c) A determinação de seu público alvo. Sugere ainda o enlace a partir da integração potencial entre estes três campos. Identificamos que a expressão competências poderia também ser acrescentada ao rol das áreas a serem investigadas para se forjar este perfil. E decorrente destas, um item a mais, o das competências necessárias ao ensino, dentre elas, a ética.

A matriz curricular é apontada como a terceira etapa metodológica e que segundo Barriga Diáz et al. (1990) é um ponto a ser discutido com os pares envolvidos no processo a partir da fundamentação desenhada na primeira etapa e o arquétipo traçado. Só então é que se esboçará a organização desta, quer seja por áreas, temas ou conteúdos, em diferentes alternativas curriculares (linear por disciplinas, modular, integrado, por competências, etc.).

Por último, sugere a avaliação como intermediária no acompanhamento dos resultados previstos no projeto pedagógico curricular.

Acrescentamos a estas reflexões que um modelo de formação para o pedagogo teria de possibilitar a troca de conhecimentos sobre 
A Ética como Competência Profissional na Formação

os diversos modelos formativos, que englobassem metodologias curriculares que se adequassem à discussão da ética enquanto competência macro e transversal ${ }^{1}$ das demais. Importante ainda ter como norte o arquétipo reflexivo sob a perspectiva humanista. Isto porque compreendemos que o desenvolvimento das competências profissionais deve se lançar à frente da cultura de trabalho em que está inserida. Os hábitos culturais forjados merecem ser questionados. É preciso cruzar a rota certeira na promoção de câmbios focados a priori nos processos de aprendizagem, socialização e humanização do profissional.

Concordamos com Freire (2011) que não é possível formar seres humanos sequer longe da ética, quanto mais fora dela. E esta é uma questão que não poderá ser deixada ao critério restrito de cada um dos sistemas educacionais, das instituições de ensino, dos professores, dos alunos, etc., esta é uma decisão que exige intencionalidade e dialeticidade entre mentes pensantes e sensibilidades atuantes.

A ética profissional ao ser entendida como competência macro, não poderá ser apadrinhada por uma formação fragmentada, ou manter-se sob um status minimizado em relação a outras áreas do conhecimento. Há que se edificar uma nova cultura escolar, humana, em que a atitude ética reflexiva se cunhe como prática, como competência. Eis aí a perspectiva de um caminho para desatar muitos nós e abrir espaços para novos jogos epistemológicos, novos constructos. Este é um ponto do qual não se pode abrir mão.

\section{Considerações Finais}

O estudo sobre competências tem sido motivo de interesse em vários campos profissionais, tendo inclusive motivado o surgimento de diversos programas de formação de professores entre as décadas $60 \mathrm{e}$ início de 80 do século XX, nos Estados Unidos, assente nas ideias de que o desenvolvimento de micro competências se constituiria no protótipo luz para forjar profissionais de excelência no campo da educação. Entretanto, o modelo da complexidade sistêmica viria a se apresentar como uma nova possibilidade, mais concreta para se atingir este ideal, especialmente por seu caráter holístico.

Sobre a formação do pedagogo, é notório que seu papel na sociedade se transformou, isto porque seu ofício não se restringe à docência, envolve hoje uma multiplicidade de saberes, fazeres o que denota a emergência na arquitetura de competências complexas, ancoradas em componentes dos mais diversos, do aprender a aprender, da interação relacional, da dialogicidade, do trabalho cooperativo, etc. Competências que remontam o paradigma epistemológico sistêmico, da complexidade e que embutem em si, a abordagem humanística. É nesta perspectiva que a ética se consolida como dimensão estruturante, mediadora, que com base em sua conjuntura constitutiva, conceitual, axiológica, deontológica e contextualista, anuncia-se como imprescindível na construção de um profissional competente. A ética é mais do 
que uma ferramenta essencial para seu desenvolvimento, compreendemo-la como competência autônoma, que não se constrói ao acaso, ou num pedacinho no meio do nada. Mas que reclama uma incursão séria frente ao planejamento de um modelo formativo exequível. Formação que consiste em forjar conhecimentos, saberes, habilidades, atitudes, capacidades, valores e naturalmente, competências, para uma melhor integração ao mundo do trabalho e que prepare o pedagogo para uma ação permanente na transformação de si próprio e dos outros, entendendo o ato de educar sob o prisma humanístico, uma prática de gente a gente, conforme o exposto nas palavras de Freire (2011):

Foi sempre como prática de gente que entendo o quefazer docente. De gente inacabada, de gente curiosa, inteligente, de gente que pode saber, que pode por isso ignorar, de gente que não podendo passar sem ética se tornou contraditoriamente capaz de transgredi-la (Freire, 2011, p. 142).

Para se atingir um estado da arte da ética como competência macro nos cursos de Pedagogia, percebemos ser necessário formular novas estratégias de ação no desenvolvimento da formação inicial. Compreendemos que não se pode criar um cientista da educação, abstendo-nos aqui do sentido tecnicista (embutido subliminarmente na expressão), equidistante da sensibilidade e, portanto, da ética. Componente curricular que como no conto da Bela Adormecida, precisa se fazer despertar, deixar de ser o patinho feio, desabrochar em cisne no âmago dos próprios cursos de Pedagogia. E logo, debruçar-se na intenção de forjar um entendimento quanto à sua melhor forma de organização curricular, se de índole transdisciplinar, interdisciplinar, multidisciplinar, integrada ou em direção a um itinerário disciplinar, que abarcasse mais do que o caráter instrucional, que fosse includente da ética em situações práticas, compondo um link com o estágio supervisionado e com as disciplinas que lhe dão suporte.

Enfim, é um jogo nada fácil de ser jogado. Isto porque no senso comum, conforme já explicitamos, percebemos a defesa da ética como tão somente forjada a partir do exemplo ou então, entendida como tarefa da família, da igreja, ou de outras instituições tomadas exclusivamente como de natureza formativa. Não descartamos o exemplo de pessoa a pessoa como parte singular no ensino da ética. A aprendizagem também se faz pelo exemplo. Questionamos, entretanto, a concepção de que ética se ensina tão somente pelo exemplo, abstendo-a do contexto da prática de ensinagem. Isto porque sustentamos que a ética é práxis e, portanto, se pode ser praticada, pode ser ensinada. A escola cabe muitas tarefas, mas especialmente ensinar o ser humano a como melhor pensar, como melhor agir e finalmente, a como ser uma pessoa melhor. E aos cursos de Pedagogia forjar profissionais eticamente competentes para este propósito. Fim de jogo. Será?

Recebido em 07 de outubro de 2014 Aprovado em 23 de junho de 2015 
A Ética como Competência Profissional na Formação

\section{Nota}

1 Na intenção de deixar clara nossa posição teórica, assumimos neste trabalho que a ética é dimensão práxis transversal em razão de interpenetrar de uma forma ou de outra as demais competências profissionais, por ser parte inegável sentido de bem como parte de sua natureza, concepção já discutida. Posição diferente no que tange ao debate da transversalidade como abordagem metodológica de organização curricular.

\section{Referências}

ALLAL, Linda. Aquisição e avaliação de competências em situação escolar. In: DOLZ, Joaquim; OLLAGNIER, Edmée (Org.). O Enigma da Competência em Educação. Tradução de Cláudia Schilling. Porto Alegre: Artmed, 2004. P. 79-93. APPLE, Michael Whitman. Educação e Poder. Porto Alegre: Artes Médicas, 1989. APPLE, Michael Whitman. Ideologia e Currículo. São Paulo: Cortez. Editora, 2006.

BERNSTEIN, Basil. Classes e pedagogia: visível e invisível. Cadernos de Pesquisa, São Paulo, n. 49, p. 26-42, maio. 1984.

BERNSTEIN, Basil. Poder, Educación y Conciencia. Santiago: CIDE, 1988.

BOTERF, Le Guy. A competência do profissional: saber administrar uma situação profissional complexa. In: BOTERF, Le Guy. Desenvolvendo a Competência dos Profissionais. Porto Alegre: Artmed, 2003. P. 37-92.

BRASIL. Decreto-Lei no 1.190, de 4 de abril de 1939. Dá organização à Faculdade Nacional de Filosofia. Publicado na CLBR, 1939. Disponível em: <http://www. planalto.gov.br/ccivil_03/decreto-lei/1937-1946/Del1190.htm>. Acesso em: 12 jul. 2015 .

BRASIL. Lei no 9.394, de 20 de dezembro de 1996. Estabelece as Diretrizes e Bases da Educação Nacional. Diário Oficial [da República Federativa do Brasil], Brasília, DF, 2006. Disponível em: <http://portal.mec.gov.br/cne/arquivos/pdf/ rcp01_06.pdf>. Acesso em: 15 abr. 2015.

BRASIL. Resolução CNE/CP 1, de 15 de maio de 2006. Institui Diretrizes Curriculares Nacionais para o Curso de Graduação em Pedagogia, licenciatura. Diário Oficial [da República Federativa do Brasil], Brasília, DF, 2006. P. 01-06. Disponível em: shttp://portal.mec.gov.br/cne/arquivos/pdf/rcp01_06.pdf > Acesso em: 18 abr. 2015.

CAETANO, Ana Paula Viana. La complexité et la formation éthique des enseignants. In: COMPLEXITÉ 2010 - COLLOQUE INTERNATIONAL FRANCOPHONE SUR LA COMPLEXITÉ, 2, 2010, Lille. Actes... Lille (França): Centre Interuniversitaire de Recherche en Education de Lille, 2010. P 1-13. Disponível em: $\leq$ http:// www.trigone.univ-lillel.fr/complexite2010/actes/VianaCaetano.pdf $>$. Acesso em: 18 abr. 2015.

CORTINA, Adela. Ética Mínima. 6. ed. Madrid: Ediciones Tecnos, 2000.

DÍAZ, Frida Barriga. et al. Metodología de Diseño Curricular para la Educación Superior. México: Trillas, 1990.

ESTEVES, Maria Manuela. Construção e desenvolvimento das competências profissionais dos professores. Sísifo. Revista de Ciências da Educação, Lisboa, n. 8, p. 37-48, 2009. Disponível em: <http://centrorecursos.movimentoescolamoderna.pt/dt/3_2_formacao_professores/32_21_constru_desenv_competencias_prof_mesteves.pdf $>$. Acesso em: 22 mar. 2015.

646 Educação \& Realidade, Porto Alegre, v. 42, n. 2, p. 627-648, abr./jun. 2017. 
ESTRELA, Maria Teresa; SILVA, Maria de Lurdes. Ética Profissional e deontologia. In: CAETANO, Ana Paula Viana; ESTRELA, Maria Teresa. (Org.). Ética Profissional Docente: do pensamento dos professores à sua formação. Lisboa: Educa, 2010.

FRADE, João Carlos Gomes. Desenvolvimento de Competências dos Docentes do Ensino Superior Marítimo em Portugal e Espanha. Lisboa: Universidade de Lisboa (UL), 2014. 311 f. Tese (Doutorado em Formação de Professores) - Programa de Pós-Graduação em Ciências da Educação, Instituto de Educação, Universidade de Lisboa, 1983.

FRAGO, Viñao. Sistemas Educativos, Culturas Escolares y Reformas: continuidades y cambios, Madrid: Morata, 2002.

FREIRE, Paulo. Pedagogia da Autonomia. Saberes necessários à prática educativa. Rio de Janeiro: Paz e Terra, 2011.

GARCÍA, Carlos Marcelo. Formação de Professores - para uma mudança educativa. Lisboa: Porto Editora, 1999.

GIROUX, Henry. Escola Crítica e Política Cultural. São Paulo: Cortez, 1987.

GIROUX, Henry. Teoria Crítica e Resistência em Educação. Petrópolis: Vozes, 1986.

GÓMEZ, Angel Ignácio Pérez. Educação e socialização. In: SACRISTÁN, José Gimeno; GÓMEZ, Angel Ignácio Pérez. Compreender e transformar o ensino. 4. ed. Porto Alegre: ArtMed, 2000. P. 14-26.

LE BOUEDEC, Guy. Les Défis de la Formation Continue: développement personnel ou développement professionnel ?. Paris: L'Harmattan, 1988.

MACEDO, Elizabeth. Currículo como espaço-tempo de fronteira cultural. Revista Brasileira de Educação, Rio de Janeiro, v. 11, n. 32, p. 285-296, maio/ago. 2006.

MACEDO, Sheyla Maria Fontenele. Avaliar: a prática pedagógica do bom senso em questão. In: SEMINÁRIO INTERNACIONAL DE ESTUDOS ÉTICOS E RETÓRICOS EM EDUCAÇÃO (SIEERE), 1, 2013, Rio de Janeiro. Anais... Rio de Janeiro: Universidade Federal do Rio de Janeiro (UFRJ), 2013. P. 324-334. Disponível em: <https://drive.google.com/file/d/0B0ElT4cWxwGRMDRndldWQ3IybWc/ view?pli=1>. Acesso em: 15 mar. 2015.

MACEDO, Sheyla Maria Fontenele. Projeto de Tese de Doutorado. Lisboa: Instituto de Educação da Universidade de Lisboa (IEUL), 2014.

MACHADO, Nilson José. Sobre a ideia de competência. In: PERRENOUD, Philippe et al. As Competências para Ensinar no Século XXI: formação dos professores e o desafio da avaliação. Porto Alegre: Armed, 2002. P. 137-155.

MORIN, Edgar. La Méthode 6. Éthique. Paris: Éditions du Seui, 2004.

PECOTCHE, Carlos Bernardo González. O Espírito. 6. ed. São Paulo: Editora Logosófica 2008.

PERRENOUD, Phillippe. Dez Novas Competências para Ensinar. Porto Alegre: Artes Médicas Sul, 2000.

PERRENOUD, Phillippe et al. Formando Professores Profissionais. Porto Alegre: Artmed, 2001.

PIRES, Ana Luísa. Educação e Formação ao Longo da Vida: análise crítica dos sistemas e dispositivos de reconhecimento e validação de aprendizagens e de competências. Lisboa: FCG, 2005.

Educação \& Realidade, Porto Alegre, v. 42, n. 2, p. 627-648, abr./jun. 2017. 
A Ética como Competência Profissional na Formação

RICOEUR, Paul. Ética e Moral. Tradução de Antonio Campelo Amaral. Covilhã: Universidade da Beira Interior, 2011.

RIOS, Terezinha Azeredo. Ética e Competência. 11. ed. São Paulo: Cortez, 2001. (Coleção Questões da Nossa Época, v. 16).

SÁ-CHAVES, Idália. Os Portfólios Reflexivos (também) Trazem Gente Dentro: reflexões em torno do seu uso na humanização dos processos educativos. Porto: Porto Editora, 2005.

SACRISTÁN, José Gimeno. O currículo: os conteúdos do ensino ou uma análise prática. In: SACRISTÁN, José Gimeno; GÓMEZ, Angel Ignácio Pérez. Compreender e Transformar o Ensino. 4. ed. Porto Alegre: ArtMed, 2000. P. 119-148.

TOMAZ, Ana Carlota Teixeira de Vasconcelos Lloyd Braga Fernandes. Supervisão Curricular e Cidadania: novos desafios à formação de professores. 2007. 575 f. Tese (Doutorado em Didáctica) - Departamento de Didáctica e Tecnologia Educativa, Universidade de Aveiro, Aveiro, 2007.

VÁZQUEZ, Adolfo Sánches. Ética. 10a. ed., Rio de Janeiro: Civilização brasileira, 1987.

YOUNG, Michael. A propósito de uma sociologia crítica da educação. Revista Brasileira de Estudos Pedagógicos, Brasília, v. 67, n. 157, p. 532-537, set./dez. 1986.

YOUNG, Michael. Currículo e Democracia: lições de uma crítica à 'nova sociologia da educação'. Educação \& Realidade, Porto Alegre, v. 14, n. 1, p. 29-39, jan./ jun. 1989.

Sheyla Maria Fontenele Macedo é professora Assistente IV na Universidade do Estado do Rio Grande do Norte (UERN), Departamento de Educação, Linha de Pesquisa Ética nos Espaços Escolares e não Escolares. Investiga sobre formação, ética na educação, avaliação educacional, didática, relações sociais (na escola, família etc.), pelo Grupo de Pesquisas e Planejamento de Ensino (GEPPE) da UERN

E-mail: sheyla_macedo@hotmail.com

Ana Paula Viana Caetano é professora Dra. Associada do Instituto de Educação da Universidade de Lisboa, em Ciências da Educação, Linha de Pesquisa Currículo, Didática e Formação de Professores. Investiga sobre desenvolvimento profissional, processos colaborativos/investigativos de formação, ética/pensamento ético-deontológico dos professores, educação intercultural, comunitária e mediação.

E-mail: apcaetano@ie.ulisboa.pt 